\title{
THOR - UMA ABORDAGEM CONTEMPORÂNEA DO BILDUNGSROMAN
}

Diogo Henrique Feliciano de Oliveira*

Leonardo Maia**

\begin{abstract}
RESUMO: No presente artigo foram analisados os filmes "Thor" (2011) e "Thor: Mundo Sombrio" (2013), verificando influências e semelhanças com o processo de formação da experiência vivenciada no movimento literário alemão, o Bildungsroman (Romance de Formação). A partir da obra "Os anos de aprendizagem de Wilhelm Meister", do escritor alemão Johann W. Von Goethe, observamos a importância da formação do caráter, da moral, nessa personagem, e seus reflexos para a formação dos leitores e, no caso dos filmes de super-heróis, dos espectadores.
\end{abstract}

Palavras Chaves: Cinema; Super-heróis; Bildungsroman.

\section{THOR - A CONTEMPORARY APPROACH TO BILDUNGSROMAN}

\begin{abstract}
In this paper, we analyze the movies "Thor" (2011) and "Thor: Dark World" (2013), verifying influences and similarities with the formation process described in the German literary movement known as Bildungsroman. Based on the book "Wilhelm Meister's Journeyman Years", by the German writer Johann W. Von Goethe, we observe the importance of character formation, morality, and its reflexes for the formation of readers and, in the case of superhero movies, viewers.
\end{abstract}

Key words: Cinema; Super heroes; Bildungsroman.

\footnotetext{
* Licenciado em Educação Artística pela Universidade Federal do Rio de Janeiro (UFRJ). Professor do Ensino Médio na cidade de Petrópolis. Email: diogofelicianooliveira@gmail.com ORCID: 0000-0002-6152-7135

** Doutor em Filosofia pela Pontifícia Universidade Católica do Rio de Janeiro. Professor de Filosofia da Educação na Universidade Federal do Rio de Janeiro (UFRJ). E-mail: leomaiabm@gmail.com

https://orcid.org/0000-0002-2080-9259
} 
$\mathrm{Na}$ epígrafe de seu livro dedicado ao universo dos super-heróis, Grant Morrisson ${ }^{1}$ evoca o Zaratustra, de Nietzsche: “Vede, eu anuncio-vos o Super-homem: é ele esse raio! É ele esse delírio!” A muitos ouvidos filosóficos, essa associação soará, talvez, risível. Nada, em princípio, permite misturar o super-homem (übermensch) nietzschiano aos super-heróis dos quadrinhos, que aportam na contemporaneidade desde as primeiras décadas do século passado. Mas seria tal associação indevida de todo? Afinal, o que devemos depreender da imagem nietzschiana? Como entender o que é o seu superhomem? A resposta para isso é muito incerta. O super-homem de Nietzsche não parece, com efeito, poder ser confundido com heróis hipertrofiados, de pele verde ou uniforme colante com símbolo de aranha. Mas, num sentido amplo, o super-homem nietzschiano é, como ele próprio o afirma, uma anunciação. E, com isso, como em toda anunciação, também uma prefiguração, uma preparação, e mesmo uma formação - uma ideia e um ideal de e em formação. Um signo, que vem antes, de algo que poderá vir depois, caso se confirme o que essa anunciação apenas desvela. Incertamente, de forma alusiva ou metafórica, o super-homem nietzschiano procura funcionar como um aceno e uma promessa: um chamado inicial para um mundo não apenas humano, para algo que está para além do homem, mas que, por isso mesmo, deve servir como seu principal móvel, como orientação de sua própria vontade de potência, que lhe impõe ser-mais. Um signo, enfim, de que a própria condição humana é, sobretudo, passagem e transição. E, portanto, que o processo de formação - em particular enquanto formação de subjetividade -, é contínuo.

Assim, ao menos um elemento da concepção nietzschiana ressoa no universo dos heróis da Marvel, DC e outras: o de que o homem não é ele mesmo um horizonte, uma culminação. E, a seu modo, esses super-herois também, postuladamente funcionariam como uma preparação para uma condição além da presentemente experimentada pelos homens, um forçamento, ao menos da nossa sensibilidade, da nossa imaginação, para além de nossa experiência atual. É assim que muitos dos quadrinistas, roteiristas e desenhistas dos 'supers' os veem. Funcionando ao mesmo tempo como um convite, uma promessa, uma incitação. Algo, de todo modo, que faça o leitor, e posteriormente já o espectador, olhar para além de si mesmo, vislumbrando outro tipo de horizonte e de compromisso. Nesse sentido, Morrison evoca a perspectiva humanista já presente na obra renascentista de Pico dela Mirandola:

Pico nos diz que temos a tendência de reencenar as histórias que contamos. Aprendemos tanto (e às vezes mais do que nos é útil) com nossos modelos de conduta ficcionais quanto com as pessoas reais com quem dividimos a existência. [...] Se cunharmos contos de culpa e fracasso com finais infelizes, viveremos essa história até sua conclusão, e uma geração final desinformada e não muito distante vai pagar a conta. Se, por outro lado, enfatizarmos a glória, a inteligência, a graça, a generosidade, a diversidade, a honestidade, a capacidade de amar, a criatividade e o gênio natural, essas qualidades serão manifestas em nosso comportamento e nossas obras.

\footnotetext{
${ }^{1}$ Roteirista de quadrinho, responsável, dentre outros, pelo roteiro da célebre HQ do Batman, Arkham Asylum.
} 
$\mathrm{Na}$ sequência desse trecho, Morrison associa, então, essa condição à função exercida pelas HQs de heróis em nosso imaginário, com o efeito deliberado de incitá-lo a uma estranha experimentação:

Devia nos encher de esperança ver que as histórias de super-herói florescem por todos os lados, pois são um sinal claro da nossa necessidade de ir adiante, de imaginar quão melhores, mais justas e mais pró-ativas as pessoas podem ser. [...] Se Pico estiver correto, podemos escrever novas vidas e novos futuros e, o mais importante, vivê-los. As histórias podem partir corações ou fomentar revoluções. As palavras podem carregar nosso coração com eletricidade ou fazer nosso sangue esfriar. E a ideia de Superman é tão absolutamente real quanto a ideia de Deus. [...] Pico está nos falando do poder que têm as histórias e a imaginação para dar forma ao futuro. [...] Embora suas metáforas sejam bíblicas, sugerindo querubins, serafins e intermediários na rota a 'Deus' ou à 'consciência cósmica', podemos da mesma forma chamá-la de super-heróis (MORRISON, 2012, p. 466-467).

E, talvez essa condição já seja ela mesma atual (ou virtual, em regime de coalescência com a atual). Como aponta ainda Morrison, “em vários sentidos, nós já somos super-humanos”. E, pelo menos dois desses 'vários sentidos' justificam, para ele, a pertinência do mundo ficcional dos super-heróis. Um, com sinal, digamos, passado; outro, porém em continuidade com esse primeiro, apontando para o futuro. Nas duas direções, parece revelar-se uma condição super-poderosa - em relação ao que se vê feito, realizado, ao extraordinário conjunto das realizações humanas até hoje, e, a partir disso, em relação ainda, com sinal futuro, ao que se antevê desde já para ela. Ou além dela.

Há muito de super-heroico no fato mesmo de não termos precisado, ainda, de super-herois. E, com isso, eles nos forçam a perceber, pela diferença naquilo que são, a diferença especial presente naquilo que já somos. No que fazemos e temos feito. No que podemos ou possibilitamos. No que devemos e, mais ainda, no que devimos:

Ser extraordinário faz tamanha parte de nossa herança como seres humanos que muitas vezes não percebemos o que já fizemos e como tudo é singular. Construímos máquinas que expandem nosso alcance físico e o alcance de nossos sentidos, permitindo que vislumbremos as profundezas do espaço e do tempo. Nossas máquinas espaciais são os filamentos físicos remotos da nossa espécie, lançados sobre abismos de nada para caírem em outros mundos ou viajar. [...] Essas superextensões dos sentidos humanos levam nossa consciência ao escuro absoluto e congelante a 16,927 bilhões de quilômetros do ponto onde você está sentado. Enquanto escrevo, é onde a Voyager 1, o dedo mais alongado da humanidade, já chegou. [...] Já existe tecnologia que permite que as pessoas dirijam carros com controle remoto mental. O que impede alguém de tornar-se Automan, o Carro humano? Individualmente, humanos não são super, mas o organismo do qual todos fazemos parte como células minúsculas certamente é. [...] Já somos parte de um superser, um monstro, um deus, um processo vivo que é tão abrangente que se torna para uma vida individual o que a água é para os peixes. Somos células no corpo de uma forma de vida singular com três bilhões de anos, cujas raízes estão nos oceanos précambrianos e cuja fiação genética estende-se pelas estruturas vivas de tudo no planeta, conectando tudo que já foi vivo num único e imenso sistema nervoso (MORRISON, 2012, p. 139). 
Essa experiência acumulada faz, então, vislumbrar um futuro de uma humanidade cada vez mais 'super'. Cujas experiências parecerão cada vez mais fantásticas, e em que a alteração bionte, nanotécnica, genética talvez seja afinal tão disseminada que será preciso rever o próprio conceito de vida. Nesse caso, mais uma vez, os super-heróis de HQ se antecipam a esse cenário. São, também eles, uma espécie de preparação, como dizíamos: “Os super-heróis podem ter o seu maior valor num futuro em que seres super-humanos de verdade estiverem buscando modelos de conduta. [Para] os super-homens do amanhã, nada melhor do que buscar orientação com Superman"2.

Essa última afirmação de Morrisson dá, então, sustentação à hipótese que gostaríamos de apresentar nesse trabalho. Entendemos que os super-heróis dos quadrinhos, sobretudo a partir da sua mais recente transposição para o cinema, têm tido um crescente alcance sobre a subjetividade contemporânea, em particular das crianças e dos jovens, constituindo um elemento relevante da sua formação. De algum modo, os super-heróis de hoje, e em especial, os super-heróis no cinema, vêm assumindo o papel inspirador e exemplar que coubera aos personagens literários tempos atrás.

Nesse sentido, procuraremos ressaltar nesse artigo algumas das características do Bildungsroman dos séculos XVIII e XIX, considerando a sua importância e novidade para a definição, com sentido mais forte, de uma função educativa para a literatura, e por extensão para todas as artes e, então, a sua possível continuação, com sinais contemporâneos, nos filmes de super-herois recentes.

Analisaremos, em particular, a personagem Thor, e dois dos filmes em que essa personagem tem presença destacada, buscando registrar como a história que marca o seu desenvolvimento coincide em vários aspectos com as narrativas que definem a condição do romance de formação. Em especial, tratase, nos dois casos, de uma reflexão, e em alguma medida, também de uma auto-reflexão, acerca do sentido de formação, e particularmente, do sentido de sua própria formação, como homem e como (super) herói.

\section{Do Bildungsroman aos quadrinhos (e filmes!) contemporâneos}

Acompanhamos um crescente aumento no número de filmes de super-heróis, baseados nas histórias em quadrinhos, sobretudo nos últimos quinze anos. Pretendemos entender de que maneira se dá o processo de identificação dos leitores, e hoje em especial dos espectadores, com estas histórias, e a razão de seu recente (ao mesmo tempo que crescente) sucesso. Nossa hipótese é que um dos elementos que concorre para a recepção favorável das novas histórias de super-herói é o fato de elas se apresentarem como histórias-de-formação, ou seja, como relatos da formação experimentada por uma determinada personagem, em geral jovem, e cuja transformação formativa é, justamente, o núcleo da história

2 MORRISON, Grant, op. cit., p. 140. 
apresentada. Com isso, os atuais filmes de super-heróis aproximam-se do modelo literário consagrado nos séculos XVIII e XIX, do chamado Bildungsroman, ou seja, do romance de formação ou de aprendizagem.

Em particular, nosso propósito é o de mostrar, através do processo de formação que marca a personagem do herói Thor, em sua concepção, criação e posterior adaptação para o cinema, como a narrativa fílmica se aproxima aos princípios narrativos que configuravam o processo de aprendizagem característico do Bildungsroman.

\section{Significado do romance de formação}

O Bildungsroman, ou romance de formação, representou um importante marco na literatura alemã, na passagem do século XVIII para o XIX. Como assinala Mazzari, “o termo 'romance de formação' foi empregado pela primeira vez por Karl Morgenstern, numa conferência proferida em 1810, com o título 'Sobre o espírito e a relação de uma série de romances filosóficos"’’3. Com esse nome, Morgenstern designara como romance de formação aqueles romances cuja personagem principal experimenta um processo de desenvolvimento espiritual, psicológico, social e político ao longo da narrativa.

Segundo Wilma Mass, esta nova literatura reestrutura radicalmente alguns cânones literários, colocando em evidência as questões da formação do indivíduo face à realidade política da época:

A palavra Bildungsroman conjuga [...] dois termos de alta historicidade no contexto alemão e mesmo europeu. Por um lado, a incipiente classe média alemã movimenta-se em direção à sua emancipação política, processo que se reflete na busca pelo autoaperfeiçoamento e pela educação universal. A par disso, cristaliza-se o reconhecimento público de um gênero literário voltado para a representação do próprio ideário burguês, gênero esse que o século XIX irá conhecer como a grande forma do romance realista (MAAS, 1999, p. 22-23).

Com efeito, desejo de emancipação e representação das possibilidades formativas dentro de um protocolo ou de um ideário burguês são dois elementos constituintes d'Os anos de aprendiragem de Wilhelm Meister ${ }^{4}$, do escritor e poeta alemão J.W. von Goethe que, com essa obra, inauguraria o movimento literário do romance de formação. Meister, o personagem principal da trama goetheana, vive em uma sociedade aristocrática, sendo ele um burguês em busca da sua formação (que, de início, mostra-se limitada, definida ou mesmo condicionada pelo ambiente que o cerca). Num primeiro momento, Wilhelm busca esta formação de maneira individualizada, através do que poderíamos considerar uma autoformação. Ele rejeita os desígnios esperados para ele, que lhe impõem uma determinada direção

\footnotetext{
${ }^{3}$ MAZZARI, 2006.

4 GOETHE, J.W. Os anos de aprendizagem de Wilhelm Meister, tradução de Nicolino Simone Neto, São Paulo, Ed. 34, 2006.
} 
educacional burguesa, negocial, e busca, em nome de uma formação mais plena, fazer novas experiências. Assim, através da sucessão de encontros que marca o livro, vão se relacionando com ele diversas pessoas que, aos poucos, vão modelando o seu caráter, seu pensamento, enfim, remodelando a própria personagem.

O principal eixo formativo experimentado por Meister é o teatro. Constitui a primeira fase de sua educação, em que prevalece toda uma busca autoconsciente em que, através das suas escolhas, ao abandonar os negócios da família, passa a viver uma vida em meio aos palcos (incluindo uma curta passagem circense); nessa opção alternativa, ele começaria a experimentar a sensação de se sentir pleno em si mesmo. Num segundo momento, por intermédio de terceiros, Wilhelm se convence de que, para alcançar a sua formação plena, deverá abandonar o teatro. No momento em que ele interpreta a peça de Willian Shakespeare, Hamlet, Wilhelm chega ao ápice de sua potencialidade como ator, e ultrapassa a todos os atores com o qual aprendeu algo, sendo ele, então, já o melhor de todos. É também nesse momento que se depara com a incerteza sobre a vida de ator

Nesse momento de ruptura com o Teatro (a imagem mais ampla envolve o abandono da própria Arte), o protagonista encontra-se sem rumo, inquieto em suas angustias. É quando acaba, nas partes finais da obra, por descobrir a Sociedade da Torre, onde (re)encontra diversos personagens de sua caminhada. O verdadeiro sentido, e o valor pedagógico de sua jornada então se revelam por inteiro: em seus encontros, de aparência fortuita, casual, ele conhecera, na verdade, os seus 'educadores'.

A partir da obra inaugural de Goethe, o Bildungsroman reverberou e reverbera em todas as literaturas ocidentais, e todas elas receberam, direta ou indiretamente, a sua influência: “[...] o Bildungsroman firmou-se como um conceito produtivo em quase todas as literaturas nacionais de origem europeia, tendo sido assimilado também nas literaturas mais jovens, como as americanas" (MAAS, 1999, p.13).

Fica evidente que esta influência se estendeu aos tempos atuais, a todas as formas narrativas, para além, inclusive, da forma literária, como uma verdadeira estratégia de aproximação com o leitor e com as questões mais diretamente ligadas ao seu cotidiano, assim como com o universo habitual de suas preocupações (em que a educação, sem dúvida, assume um papel crucial).

Neste sentido, cabe destacar, em particular, duas novas 'mídias': os quadrinhos, também chamados de 'HQs' ou 'comics', e o cinema. Elas se valerão, reiteradas vezes, do modelo anterior do romance de formação, com variantes, especialmente, como veremos, nas aventuras que envolvem os super-heróis. 


\section{O romance de formação e a narrativa de super-heroi, das HQs aos filmes}

Em 1938, surge a primeira história em quadrinhos de super-herói ${ }^{5}$, nos EUA. Naquele momento, ainda se podiam sentir os reflexos da crise de cerca de nove anos atrás, que devastara a economia do país e do mundo. Em junho daquele ano surgia, então, Superman. Era também um momento pré-Segunda Guerra, ou já de início dela, e em meio aos novos riscos, tão próximos historicamente da crise anterior, e talvez mesmo ao profundo caos que se prefigurava, surgiam como ideia nova, nos quadrinhos, resoluções fantásticas para dramas reais. Não se tratava de simples escapismo. Nem de um retorno ao "maravilhoso", com uma atualização, em chave contemporânea, dos contos de fada. O apelo inicial desses primeiros heróis parece antes de tudo de ordem ética, envolvendo valores com sinais muito claros: exemplaridade, integridade, companheirismo, solidariedade... Em um momento no qual uma grande crise (econômica) parece se resolver em outra de ainda maiores proporções (política e militar), isso parece ocorrer em razão de uma terceira crise, ética, que se afigura mais profunda, de valores em declínio. Os autores das HQs de então parecem partir daí, desse aparente sentimento de descrença cada vez maior em relação aos valores postos, ou ao menos do real compromisso dos homens para com eles. Seria preciso um 'super' para ainda acreditarmos, através dele, em algum valor, antigo ou novo. Para nos fazer crer, mais uma vez, em nosso mundo.

Os quadrinhos significavam, assim, para aqueles jovens e adolescentes, capacidade e força de superação das adversidades, esperança de um outro mundo possível. Em suas heroicas qualidades e superiores possibilidades, os novos super-heróis contrastavam com uma realidade que se afigurava por demais sombria e incerta.

Muitos heróis surgiram desde esse momento inicial, fossem, efetivamente, como novos personagens, que se valiam de histórias e ideias originais, ou outros, que se mostravam cópias extremamente grotescas dos heróis mais clássicos (na esteira, por exemplo de Superman e Batman). A chamada Era de Ouro $^{6}$ dos quadrinhos duraria vinte anos e, ao seu final, temas como a guerra já não contemplavam mais os pensamentos mais presentes dos jovens. Foi então que se definiram novas demandas e novas formas de escrever quadrinhos. Estas envolveram, em particular, uma mudança de perspectiva: em lugar de tomar o super-herói como um ponto de vista (justo, ético, corretor) sobre o mundo à sua volta, a novidade foi a de tornar os próprios supers objetos de avaliação e problematização. De modo geral, o foco se alterava daquilo que os heróis faziam (seus super-poderes, suas formas de ação,

\footnotetext{
${ }^{5}$ As definições mais usuais de 'herói’ apresentam-no, segundo um termo derivado do grego antigo, como significando "homem com qualidades magnânimas; semideus". Outra definição é a de um "homem extraordinário por seus feitos guerreiros", ou ainda "homem admirável por feitos e qualidades nobres"(LOEB, J., MORRIS, T. in IRVIN, 2009, p. 25).

${ }^{6}$ Era de ouro foi o período destacado por Grant Morrisson (2011) como o do boom marcado pelo surgimento das HQs de super-herois, e que durou em torno de 20 anos, chegando até 1958.
} 
seu combate permanente ao mundo do crime e aos super-vilões) para o que eles são, ou ao menos para uma melhor relação entre ambas as situações - o que se é, e como, naquilo que se faz.

A consolidação dessa nova perspectiva acaba por necessariamente envolver, nessas tentativas de se buscar entender o porquê de serem eles o que são, uma questão pedagógica: o tipo de formação que tiveram, a auto-educação que estão obrigados a se impor enquanto supers etc. Isto é, quando a Marvel começou a valorizar os processos de consolidação dos heróis, sua psicologia, seu desenvolvimento e sua aprendizagem, tornou-se claro que a sua situação de super era, sobretudo, exterior, em relação aos efeitos e eventos que eles eram capazes de produzir no mundo. Inversamente, eles não eram ou não pareciam ser tão super assim por dentro. Ao contrário...

Mesmo por sua condição extraordinária, a sua vida pessoal e as suas questões existenciais denunciavam uma subjetividade em crise, ou mesmo, em farrapos. Admirado por todos, ao mesmo tempo que distante de todos. Incompreendido, e sozinho... Surgiram, nesta época, os principais personagens do universo Marvel, tais como Capitão América, Homem-Aranha e Thor. Estes heróis tinham como principal móvel não exatamente vencer vilões fabulosos ou adversários igualmente superpoderosos mas, sobretudo, lidar consigo mesmos. E, também, por conta disso, com as questões comezinhas do dia-a-dia: problemas familiares, amorosos... E, muitas vezes, expunham, paradoxalmente, considerados os seus fantásticos super-poderes, a sua impotência em resolvê-los. Nestes novos superheróis, ao contrário dos heróis clássicos, as situações retratadas eram cotidianas, e, portanto, eram também cotidianos os seus problemas e dificuldades. Vemos, por exemplo, um Peter Parker excessivamente egoísta, e cuja impulsividade e negatividade adolescente implicou na morte do próprio tio. Ou um Thor arrogante, e mandado então à Terra, para ali amadurecer, e com isso fazer jus à condição de sua própria divindade.

Os super-herois, ao mesmo tempo que grandiosos, mostram-se frágeis - a tônica das novas HQs está em explorar tal ambivalência, mostrá-los em toda a sua ambiguidade. Mas, com isso, o seu impacto sobre os leitores começou a se alterar significativamente. A relação esperada com os jovens leitores não iria apenas na direção de mostrar suas incríveis ações, ou os seus super-poderes produzindo uma existência extraordinária, mas, ainda, tencionava produzir uma nova relação especular com seus leitores, cujos problemas passam a ser vistos como comuns aos seus próprios heróis.

A figura dos modernos super-heróis alterava-se fortemente. Essas novas histórias eram escritas para mostrar o quão normal é ser jovem, e todas as confusões e conflitos que tal condição traz. A partir de então, os quadrinhos desempenharam uma forte função formativa, na qual, para além da execução de uma ação, eram valorizadas as razões e motivações que definiam e explicavam essa ou aquela ação, e até mesmo as escolhas e experiências que trouxeram o herói até ali, para que tivesse de executar tal ação. Ou seja, como no romance de formação, a formação do herói assume forma especular, e aparece como 
possibilidade de experimentação para a própria formação do leitor. De um lado, para sobreviver, os heróis tiveram de se redefinir, adaptar-se para se adequar às novas demandas para as suas histórias; de outro, o leitor pode também ligar essas histórias à sua própria realidade.

É o caso do Superman, que volta repaginado na série Smallville (2001), narrando-se desde a sua adolescência, e do Batman, em que se apresenta o processo de aprendizado de Wayne, até tornar-se o justiceiro mascarado. Assim, Adriano Lima Drummond, no artigo "O Batman de Christopher Nolan: formação e deformação do herói", aproxima o processo de formação do personagem com o processo de formação característico do Bildungsroman. No artigo, o autor destaca alguns traços da influência do Bildungsroman na abordagem fílmica do Batman, e ressalta como esta envolve o processo da formação do herói, ao mesmo tempo que um processo paralelo de deformação (caso de Harvey Dent). Nesse caso, mais uma vez, a história gira em torno não exatamente do herói, mas dos acontecimentos e personagens que aparecem como peças fundantes da trama, configurando em seu conjunto toda uma rede formativa. Os personagens 'coadjuvantes' assumem aspecto central na narrativa, inclusive tornando o herói de algum modo 'secundário' em sua própria história (por exemplo, o Coringa, em o Cavaleiro das Trevas). Exatamente como no Bildungsroman goethiano, em particular, no Wilhelm Meister: o processo (formativo) é o mais importante, e não a personagem.

Podemos perceber, tal como no Bildungsroman de Goethe, um aprendizado que é evidenciado para o espectador. É dada, então, tanta importância à formação do personagem, como também à do próprio espectador.

\section{O personagem Thor e a história-de-formação apresentada no filme}

No filme "Thor" (EUA, 2011), com direção de Kenneth Branagh, o personagem principal apresenta uma característica muito diferente em relação ao deus presente originalmente no mito.

A mitologia nórdica foi passada de geração para geração através de Eddas ${ }^{7}$, mas apenas no séc. XIII, o islandês Snorri Sturluson (1179 - 1241) irá codificar grande parte destes mitos. ${ }^{8}$ Thor aparece nas histórias mitológicas dotado das características extraordinárias, que marcam uma personagem divina. Ao mesmo tempo, se destaca pelo seu conhecimento e força sobre-humanos e pela capacidade de ação à toda prova. Neste sentido, não apresenta nenhum tipo de preocupação com qualquer tipo de aprendizagem, pois apresenta todas as características de um herói pronto e acabado. Thor carrega consigo, sem nenhum peso,

\footnotetext{
${ }^{7}$ Eddas são a forma com que se estruturou narrativamente a mitologia nórdica. Eram histórias passadas de forma oral, que posteriormente foram compiladas em prosa, o que permitiu maior acesso a essas narrativas.

${ }^{8}$ As melhores histórias da mitologia nórdica. A.S. Franchini e Carmen Seganfredo, $13^{\mathrm{a}}$ ed.- Porto Alegre, RS, Artes e Ofícios Editora, 2014, p. 7. A partir da Edda em Prosa, A.S Franchini, em parceria com Carmem Seganfredo, escreveram o livro "As melhores histórias da mitologia nórdica", principal versão de circulação dessa mitologia no Brasil. A partir dos contos desta obra, tecemos uma análise sobre as características do deus Thor e seus desdobramentos na mitologia.
} 
a alcunha de "Thor, o matador de gigantes", alcunha reivindicada por ele em diversos momentos. Apresenta, ainda, uma característica muito peculiar, de uma arrogância que mal cabe dentro de si.

Com base nessas características, afirmamos então que Thor aparece na mitologia como o que poderíamos chamar de 'tipo clássico' do Herói, capaz de feitos extraordinários. Em linhas gerais, essa condição é a de um sujeito-que-age. Thor aparece assim como um protagonista, um sujeito ativo, sempre empreendendo alguma ação. Em consequência disso, a trama narrativa de seus feitos mitológicos passa centralmente por ele, todos os outros personagens são secundários frente a ele, giram em torno ou comparecem à história solicitando-o e, finalmente, a partir da sua ação e de suas realizações se dá, enfim, o desfecho da trama. Esta perspectiva sobre Thor, personagem mitológico-literário dos Eddas, apresentará alguma mudança quando o herói legendário e mitológico é transposto para as HQs e se transmuta no super-herói da Marvel.

\subsection{Thor: Um novo super-herói.}

Thor tem a sua primeira aparição nos quadrinhos em 1962, no início da Marvel, no Journey into Mystery, No 83, criação conjunta de Stan Lee, Lerry Lieber e Jack Kirby. Com história baseada no mito do deus nórdico, Thor aparece em suas primeiras histórias combatendo seres da sua e até de outras mitologias. Porém, ele só é mostrado como deus quando Stan Lee assume os roteiros dos quadrinhos?. No roteiro proposto por Lee, Thor, que era visto por seu pai, Odin, como um deus extremamente arrogante, foi punido com uma maldição pelo mesmo Odin (Pai de todos): ele deveria perder o seu martelo Mjolnir e cumprir um exilio em Midgard (Terra), para aprender lições de humildade. Como parte da punição, Thor só poderia ter de volta o seu martelo, quando aprendesse tais lições. Pois, ainda segundo o roteiro de Lee, apenas seria digno de empunhar o Martelo, aquele que tivesse caráter íntegro.

Neste exilio na terra, Thor perde a sua condição, e mesmo a memória divina. Ele se torna um personagem com natureza humana, de nome Donald Blake, um médico brilhante, manco de uma perna e que, aos poucos, salvando vidas ainda como médico, vai aprendendo lições para que, enfim, seu destino pudesse se cumprir e ele se tornasse novamente o deus Thor.

Thor tem sua primeira representação em filmes, em 1988, em “A Volta do Incrível Hulk” (EUA, 1988; Dir.: Nicholas Correa). Donald Blake (Steve Levitt) era, então, um médico que atuava junto com alguns cientistas em uma expedição. No filme, ele é um antigo colega de trabalho do Dr. David Banner (Bill Bixby) alter-ego do Hulk. Ele pesquisava sobre a existência de um deus nórdico antigo quando, em uma caverna na Escandinávia, acha uma campa com um corpo e um martelo "sobrenatural”. Este martelo

\footnotetext{
9 Jack Kirby e Larry Lieber, roteiristas originais do personagem, mantiveram Thor como um herói "humano" (ou antes, um 'alienígena', com características humanas) empunhando um martelo com poderes; quando S. Lee assume suas histórias, Thor apresenta características de um Deus, como super-força e super-resistência.
} 
revela Thor (Eric Allan Kramer), um outro personagem, distinto de Donald Blake, mas, ainda assim, uma parte dele. Como se Thor, de maneira inconsciente, fosse dividido em dois personagens.

Donald Blake, neste filme, se apresenta como parte separada do herói, mas ao mesmo tempo parte essencial em sua jornada. Blake é a parte de Thor humilde, solícito, reflexivo, por vezes, comparado a sua porção intelectual, o cérebro no corpo poderoso, como se fora um guia na comum caminhada de ambos, e que será, afinal, a da própria formação do Thor. Com a sua ajuda, Thor vai pouco a pouco descontruindo sua arrogância e aprendendo lições de humildade, respeito e companheirismo, observando e se adaptando aos costumes de Blake e ajudando pessoas necessitadas. Ele aprende desta forma consigo mesmo, numa espécie de auto-formação a partir da exemplaridade de outro, que é, ao mesmo tempo, ele próprio.

Mais de duas décadas depois, Thor reaparece no filme homônimo de Kenneth Branagh ('Thor'; EUA, 2011), com um enredo já totalmente dedicado a ele, e vivido por Chris Hemswhorth. A história passa por severas mudanças no que tange às histórias anteriores, nos filmes ou quadrinhos da Marvel, e parece fazer, ou ao menos tentar fazer um pouco mais de sentido em relação ao Deus nórdico. O enredo da história mostra a caminhada de Thor (sem seus poderes, privado do martelo), até tornar-se o deus do Trovão.

A história começa em um momento de guerra entre dois mundos, Jotunhein e Midgard (a Terra): os Jotuns, gigantes de gelo, tomam a Terra, com a intenção de fazê-la retornar ao período Glacial. Odin (Anthony Hopkins), o pai de todos, intervém na grande batalha e salva a Terra. Mas Odin, cansado, decide escolher um sucessor ao trono de Asgard. Escolhe então Thor, filho de sangue. Enciumado com tal escolha, Loki auxilia a entrada de Jotun em Asgard, numa tentativa de roubo da pedra que concedia vitalidade em Jotunhein (planeta dos Gigantes de Gelo), impedindo, no último segundo, a coroação de Thor. Com a invasão, Thor, tomado pelo ódio e sede de guerra, demonstra uma irredutível vontade de declarar guerra a Jotunhein. Odin, o sábio rei de Asgard, entra então em conflito com Thor, e neste conflito com o pai, em que Thor reivindica para si o direito de ordem de ataque como rei, seu pai ressalta: "Você não é rei! Ainda não...", que indica ali, pela primeira vez, aspectos de uma formação incompleta, pois virar rei é o destino de Thor, mas para isso é preciso atender a um rol de características que configuram um bom rei, ou um bom herói.

Com a chegada de seus amigos, Sif (Jaimie Alexander) e os Três guerreiros, Thor tenta persuadilos a seguir seus planos e, neste momento, Fandral (Josh Dallas) lhe ensina uma valorosa lição, a primeira desde o início da sua jornada, expondo a Thor sua verdadeira condição, contrapondo-se aos seus planos; Fandral diz-lhe: "Isto não é uma viagem à Terra em que você invoca um raio, um trovão e os humanos te cultuam como um Deus". A frase demonstra toda a fragilidade e imaturidade de Thor, mesmo para seus mais fiéis amigos. Com esta simples frase, Fandral expõe o fato de Thor não possuir poderes, mas 
apenas empunhar um Martelo poderoso, o que poderia ser feito por qualquer um. Ou seja, apenas por força dos poderes do Martelo é que os humanos o veem como deus. Deus este que ele na verdade não é, pois não está pronto para esta responsabilidade. Porém, ainda assim, foi decidida a invasão, atitude que lhe traria drásticas consequências.

Em Jotunhein, Laufey (Colm Feore), o rei de Jotunhein, desdenha da presença do filho de Odin e futuro rei de Asgard. Numa discussão, ele identifica em Thor sua incompletude (não-formação), e faz uma analogia desta imaturidade com outro aspecto formativo fundamental, que é o das experiências de vida adquiridas, algo de que Thor ainda carece, em razão de sua própria juventude, afirmando: "Você não passa de um menino tentando provar para si mesmo que é um homem”.

"Vaidoso, ganancioso e um menino cruel" foram as palavras proferidas pela boca do pai, na discussão que Thor e Odin têm após o conflito, e o tema da imaturidade é trazido mais uma vez à tona. Outros desvios de seu caráter também são postos em xeque, em particular a impetuosidade irrefreada de Thor. Odin, o mais sábio de todos, admite ter errado: "Fui um tolo em pensar que você estava pronto [para assumir o trono]". Thor é banido de Asgard, e enviado para Midgard para aprender lições de moral, respeito e humildade. Odin lança naquele momento também a Midgard, Mjolnir, com uma maldição: “aquele que empunhar o martelo, se for digno, terá então o poder de Thor”.

É então na Terra que ele passará todo o seu banimento, e aprenderá tudo o que precisa para tornar-se 'novamente' pronto, ou pela primeira vez digno de verdade de empunhar um artefato de tamanha responsabilidade. Sua primeira lição na terra é a respeito do corpo, física: atropelado pela cientista Jane Foster (Natalie Portman), por duas vezes, a primeira logo assim que pisa na Terra, a outra, depois de sair do hospital, ele aprende o que é dor de verdade. O martelo o deixava mais forte, o regenerava, potencializava todos os seus atos. Sem o martelo e todos os aparatos da armadura, acaba descobrindo os limites e fraquezas de seu corpo, e com isso tomando noção de si e da própria fragilidade. Outro exemplo deste processo de aprendizado corporal foi o momento onde, assustada, Darsi Lewis (Kat Dennings), aponta para ele um teaser, e não titubeia em usá-lo. Após ser carregado para o hospital, Thor tenta escapar ao acordar, e depois de bater em 13 pessoas na enfermaria, ele fala "vocês não são páreo para o poderoso...” e desmaia com uma injeção de tranquilizante.

Saindo do hospital, depois de uma tentativa frustrada de erguer Mjolnir, em um bar, Eric Selvic, cientista e mentor de Foster, sai para beber com Thor, e é a vez de ele dar a sua contribuição na formação do seu caráter. Diz a Thor palavras decisivas, que explicitam a importância do processo formativo pelo qual está passando: "Não é ruim descobrir que não temos todas as respostas para começar a fazer as perguntas certas". E ainda, continua Eric, "Qualquer um que quiser encontrar um caminho neste mundo tem que admitir que não faz ideia de onde está”. Estas palavras tocam profundamente Thor que, pela primeira vez na sua vida, não tem mesmo muita ideia do que fazer. Neste momento, Thor identifica sua 
dificuldade em ouvir o outro, em detrimento de tudo o que já lhe havia acontecido. Este momento de formação do herói pode-se comparar ao de Wilhelm Meister, no momento do seu abandono dos palcos e sua renúncia ao teatro. Esse tem, então, de recomeçar a sua vida, que fora, até ali, totalmente devotada ao teatro, e o súbito abandono dos palcos o deixa sem novos planos.

A virada final do filme se dá quando o Destruidor ("Maquina” de Proteção de Asgard), por ordem de Loki, que tomara o trono de Odin em um golpe, desce à Terra para destruir Thor. Este, mais uma vez, recebe a ajuda de Sif e dos três guerreiros, que haviam também descido a Terra com o intuito de avisar a Thor sobre o golpe em curso. Assim que se veem frente a frente com o Destruidor, seus amigos asgardianos esperam que Thor invoque a sua força divina, mas, ao contrário, ele demonstra todas as suas limitações proferindo: "Sou apenas um homem, só iria atrapalhar, mas posso ajudar estas pessoas a chegarem a um local seguro".

Afinal, Thor, empunhando apenas um escudo, vai de encontro ao Destruidor ${ }^{10}$. Surpreendentemente, ele solta o escudo e pede desculpas diretamente a Loki, ainda sem saber o porquê. Pensa na vida de todos os inocentes e cede a sua própria. Thor torna-se, afinal, digno, e, portanto, novamente passível de empunhar o Mjonir.

Depois de derrotar sem muito esforço o Destruidor, Thor retorna a Asgard, a fim de reencontrarse com Loki. Porém Thor não quer lutar e, surpreso, indaga-lhe Loki: “O que aconteceu com você na Terra que o amoleceu tanto?’. Baseados na própria percepção de seu irmão, notamos que Thor já começa a apresentar características de humildade e compaixão, na consolidação de seu caráter. $\mathrm{O}$ ápice desse processo formativo (e de sucessivas provas, de caráter e de amadurecimento) se dá na destruição da Bifrost, quando Thor deverá abrir mão da sua vontade de morar na Terra, e do seu amor por Foster, para salvar o planeta de seus maiores inimigos, os Gigantes de Jotunhein.

Em seguida a estes acontecimentos, Thor conversa com o seu pai, sobre suas recentes experiências, sobre o seu exílio, enfim, sobre tudo o que ocorrera, e Odin o elogia: "Você será um rei sábio". Thor, agora gozando plenamente de suas faculdades, sabedor de encarnar características positivas e negativas, potências e fraquezas, retruca, reforçando a senda pedagógica que começara a trilhar: "Eu tenho muito o que aprender; agora sei disso e talvez um dia eu faça com que se orgulhe”, e assim se encerra o processo inicial de formação desta abordagem contemporânea do Deus Nórdico Thor.

\footnotetext{
10 Thor reencontra aqui o personagem mítico e literário do Eddas: sem a luva, o martelo e o cinto, no conto 'Thor e o Rapto de Loki', ele arrogantemente desafia gigantes sem seus poderes, e totalmente despido de qualquer proteção.
} 


\section{Conclusão}

Numa cultura, secular, científica e racional, que deixa a desejar em lideranças espirituais confiáveis, as histórias de super-herói falam mais alto, e com mais força frente a nossos grandes medos, nossos desejos mais profundos e nossas maiores aspirações. Elas não têm medo de trazer esperança, não se envergonham do otimismo e não têm medo do escuro. Estão o mais distante possível do realismo social, mas as melhores histórias de super-herói lidam diretamente com elementos míticos da experiência humana com os quais todos nós podemos fazer paralelo [...]. Nos ajudam a enfrentar até as crises existenciais mais profundas (MORRISON, 2012, p. 16).

O traço comum a essas novas histórias de super-heróis em relação ao Bildungsroman alemão, e à forma geral do romance de formação, situa-se, precisamente, nessa concepção da narrativa como expressão de um processo de amadurecimento e crescimento pessoal, evidenciando o processo pelo qual alguém se torna 'mais' do que era inicialmente. O romance de formação é a literatura de um moderno herói problemático, inacabado e indeterminado, em busca das qualidades que reconhece ainda não ter: ou seja, é a literatura do querer e do impor-se um devir-outro, ou um ser-mais.

O traço curioso é que, em princípio, essa situação não poderia alcançar um super-herói: ele, justamente, já é mais que um homem. Inatural, ou sobrenatural à natureza humana, e em maior grau, até, do que o herói clássico. É mais do que o comum dos homens, é mais do que todos ao seu redor. Nesse caso, a narrativa contemporânea dos supers deverá inverter, ao menos parcialmente, um dos elementos do tradicional romance de formação: o herói do Bildungsroman dos séculos XVIII e XIX se vê impelido a enfrentar um processo educativo porque se sabe menor, ao se ver como 'menos' que outros, que se destacam ou mesmo se impõem a ele, nas relações sociais, no poderio econômico, nas tramas do amor. No caso dos 'super', dá-se o preciso oposto a tal situação: por saber-se maior, mais poderoso, por isso mesmo, o herói deve conhecer-se melhor, deve educar-se para os seus próprios super-poderes Mesmo porque, na condição de supers, é a observância ética que irá defini-lo ou não como um verdadeiro (super) herói.

Como entender esses filmes, essa nova super-educação dos heróis e heroínas? Teríamos aí uma espécie de alegoria ética do momento presente? Da ascensão do hiper-capitalismo contemporâneo e de um espírito de distância presente em seus grandes predadores? Seja como for, esse traço ético, mostra-se ora como antes, absolutamente relevante:

O conceito de um herói é o que os filósofos chamam de conceito normativo. Ele não apenas caracteriza o herói, mas nos permite vislumbrar como deveríamos ser. Tem um certo poder sobre nós. Apresenta-nos algo a aspirar, na vida. Os super-heróis proporcionam grandiosas imagens fictícias, e são ao mesmo tempo inspiradores e motivadores. Quando bem desenvolvidos e retratados, eles nos dão algo que deveríamos almejar. [...] A descrição das histórias heroicas e super-heroicas é de força moral. Desde a nossa infância até a idade adulta, os super-herois podem nos lembrar da importância da autodisciplina, do autossacrifício e de nos dedicarmos a algo bom, nobre e importante. Eles podem ampliar nossos horizontes mentais e apontar nossa 
determinação moral enquanto nos entretêm. [...] É sensato sugerir que os super-herois existem há tanto tempo e continuam sendo tão populares, em parte, porque falam à nossa natureza, bem como às nossas aspirações e aos nossos medos (LOEB, Joseph e MORRIS, Tom, em IRVIN, p. 23) ${ }^{11}$.

Para alguns, a perspectiva de criação de um tal 'mundo' denota, essencialmente, um complexo de valores e aspectos negativos do contemporâneo: a decadência da alta cultura, e mesmo talvez já da cultura pop, a impossibilidade cada vez mais flagrante, para muitos, em encarar a realidade presente, uma forma, portanto de escapismo e denegação, um infantilismo generalizado. Na verdade, parece-nos que, mais exatamente, o que ronda esse mundo é uma questão muito mais antiga, e que poderíamos nomear, em síntese, como o desejo ou vontade-de-formação.

Em última análise, o maior poder dos supers está então, não naquilo que realizam, não nos seus feitos grandiosos, enormes, mas no alcance que têm sobre nós. Nessa relação especular que mantêm com o leitor/espectador. $\mathrm{Na}$ condição, em última análise, que têm de nos modificar. Foi essa, também a aspiração maior do romance de formação original.

\section{REFERÊNCIAS}

CAMPBELL, Joseph. O herói das mil faces. São Paulo: Cultrix, 1989, 11ª reimpr.

DRUMMOND, Adriano Lima. O Batman de Christopher Nolan: formação e deformação do super-herói, Teresina: Revista Desenredos, 2011.

FRANCHINI, A.S. e SEGANFREDO, Carmen. As melhores histórias da mitologia nórdica. Porto Alegre: Artes e Ofícios Editora, 2014, $13^{\mathrm{a}}$ ed.

GOETHE. J.W, Os anos de aprendizagem de Wilhelm Meister, tradução de Nicolino Simone Neto, São Paulo, Ed.34, 2006.

HOWE, Sean. Marvel Comics -- A História Secreta; Tradução: Érico Assis. São Paulo, LeYa, 2013.

IRWIN, Willian (coord.). Super - Heróis e a Filosofia: Verdade, justiça e o caminho socrático. Tradução: Marcos Malvezzi Leal. São Paulo: Madras, 2005.

IRWIN, Willian. Batman e a Filosofia: O Cavaleiro das Trevas da Alma. São Paulo: Madras, 2008.

LIEBEER, Larry e LEE Stan. “JOURNEY INTO MYSTERY (1952) \#83”, 2007. Disponível em: < http://marvel.com/comics/issue/9779/journey into mystery 1952 83/> Acesso em: 27/10/2015.

\footnotetext{
${ }^{11}$ LOEB, Joseph e MORRIS, Tom; “Herois e Super-heróis”. IRVIN, W. (Coord.) Super-Herois e a Filosofia. Verdade, justiça e o Caminho Socrático. Tradução de Marcos Malavezzi Leal. São Paulo, Madras, 2009 pág.27
} 
MAAS, Wilma Patricia Marzari Dinardo. O cânone mínimo: o Bildungsroman na história da literatura. São Paulo: UNESP, 1999.

MAIA, Leonardo e ANDRADE, Pedro Duarte de. O Wilhelm Meister de Goethe: o romance de formação e a formação como poética. Rapsódia - almanaque de filosofia e arte. São Paulo: USP.

MAZZARI, Marcus Vinicius, Apresentação: Os anos de aprendizagem de Wilhelm Meister, tradução de Nicolino Simone Neto. São Paulo: Ed.34, 2006.

MIRANDOLA, Pico dela. A dignidade do homem. São Paulo: Edições GRD, 1988.

MORRISON, Grant. Superdeuses. tradução Érico Assis. São Paulo: Seoman, 2012.

THOR. Direção Kenneth Branagh. EUA: Marvel Studios, 2005.

A VOLTA do incrivel Hulk. Direção Nicholas Correa. EUA: New world Televison e B\&B Productions, 1988.

WESCHENFELDER, Gelson Vanderlei, Os Super-heróis e esta tal de filosofia. Porto Alegre: REI, 2012. 